\title{
Impact of detectable measurable residual disease on umbilical cord blood transplantation
}

\section{Authors:}

Frédéric Baron ${ }^{1}$, Myriam Labopin ${ }^{2-5}$, Annalisa Ruggeri ${ }^{6-7}$, Jorge Sierra ${ }^{8}$, Stephen Robinson $^{9}$, Hélène Labussière-Wallet ${ }^{10}$, Michael Potter ${ }^{11}$, Josep-Maria Ribera ${ }^{12}$, Eric Deconinck $^{13}$, Alessandro Rambaldi ${ }^{14}$, Pierre-Simon Rohrlich ${ }^{15}$, Thierry de Revel ${ }^{16}$, Eliane Gluckman7, Arnon Nagler ${ }^{2,17}$ and Mohamad Mohty ${ }^{2-5}$

\section{Affiliations:}

1 Laboratory of Hematology, GIGA-I3, University of Liege and CHU of Liège, Liege, Belgium

2 EBMT Paris study office / CEREST-TC, Paris, France

3 Department of Haematology, Saint Antoine Hospital, Paris, France

4 INSERM UMR 938, Paris, France

5 Université Pierre et Marie Curie, Paris, France

6 Ospedale San Raffaele s.r.l., Haematology and BMT, Milano, Italy

7 Eurocord, Hospital Saint Louis, AP-HP, and IUH University Paris VII, France Monacord, Centre Scientifique de Monaco, Monaco

8 Hospital Santa Creu i Sant Pau, Hematology Department, Barcelona, Spain

9 Bristol Royal Hospital for Children, Dept. of Paediatric Oncology/BMT, Bristol, United

Kingdom

10 Centre Hospitalier Lyon Sud, Service Hematologie, Lyon, France

11 Royal Marsden Hospital, Leukaemia Myeloma Units, London, United Kingdom

12 ICO-Hospital Universitari Germans Trias i Pujol Clinical Hematology Department, Badalona, Spain, Spain

13 Hopital Jean Minjoz, Service d'Hématologie Besancon, France

14 Department of Oncology and Hematology, University of Milan and Azienda Socio

Sanitaria Territoriale, Papa Giovanni XXIII, Bergamo, Italy

15 CHU Nice - Hôpital de l’ARCHET I, Hematologie Clinique, Nice, France

16 Hôpital Américain, Hematology Department, Clamart, France

17 Division of Hematology and Bone Marrow Transplantation, The Chaim Sheba Medical Center, Tel-Hashomer, Ramat-Gan, Israel

\section{E-mails :}

Frédéric Baron : f.baron@uliege.be

Myriam Labopin : myriam.labopin@upmc.fr

Annalisa Ruggeri : annalisaruggeri80@hotmail.com

Jorge Sierra : jsierra@santpau.cat

Stephen Robinson : Stephen.Robinson@UHBristol.nhs.uk

Hélène Labussière-Wallet : helene.labussiere-wallet@chu-lyon.fr

Michael Potter: Mike.Potter@rmh.nhs.uk

Josep Maria Ribera Santasusana : jribera@iconcologia.net

This article has been accepted for publication and undergone full peer review but has not been through the copyediting, typesetting, pagination and proofreading process which may lead to differences between this version and the Version of Record. Please cite this article as doi: 10.1002/ajh.25879 
Eric Deconinck : edocpatch@free.fr

Alessandro Rambaldi : arambaldi@asst-pg23.it

Pierre-Simon Rohrlich : rohrlich.ps@chu-nice.fr

Thierry de Revel: thderevel@gmail.com

Eliane Gluckman : eliane.gluckman@aphp.fr

Arnon Nagler : Arnon.Nagler@sheba.health.gov.il

Mohamad Mohty : mohamad.mohty@inserm.fr

Short title: MRD and CBT outcomes

Words count: abstract: 248 words, manuscript: 2160 words.

Address for correspondence: Frédéric Baron; University of Liège, department of Hematology, CHU Sart-Tilman 4000 Liège Belgium. Tel +32 - 4 - 36672 01; Fax +32 - 4 36688 55; E-mail: f.baron@ulg.ac.be

Keywords: Acute myeloid leukemia, AML, acute lymphoblastic leukemia, ALL, minimal residual disease, MRD, umbilical cord blood transplantation, CBT. 


\section{ABSTRACT}

The impact of measurable residual disease (MRD) on cord blood transplantation (CBT) outcomes has remained debated. To address this issue, we assessed the impact of measurable MRD at CBT on outcomes in large cohort of patients with acute leukemia. Inclusion criteria included adult patients with acute myeloid (AML) or acute lymphoblastic leukemia (ALL), CBT as first allo-HCT in first or second complete remission (CR) at transplantation, and known MRD status at the time of CBT. Data from 506 patients were included in the analysis. Among them, 317 patients had AML and 189 had ALL. Positive MRD was reported in 169 (33\%) patients while the remaining 337 patients were MRD negative at CBT. At 2 years, relapse incidence was $18 \%$ in patients with MRD negativity versus 33\% in those with MRD positivity at transplantation $(\mathrm{P}<0.001)$. Two-year leukemia-free survival (LFS) and overall survival (OS) were 57\% and 60\%, respectively, in MRD negative patients, versus 38\% $(\mathrm{P}<0.001)$ and $48 \%$ $(\mathrm{P}=0.004)$, respectively, in those with MRD positivity. There was no interaction between the impact of MRD on OS and LFS and diagnosis (i.e. ALL versus AML), single or double CBT, and reduced-intensity or myeloablative conditioning. On multivariate analysis, MRD positivity was associated with a higher risk of relapse $(H R=1.8, P=0.003)$, comparable non-relapse mortality $(\mathrm{P}=0.44)$, worse LFS $(\mathrm{HR}=1.4, \mathrm{P}=0.008)$ and a trend towards worse $\mathrm{OS}(\mathrm{HR}=1.3, \mathrm{P}=0.065)$. In conclusion, these data suggest that novel strategies that are aiming to achieve MRD negativity at CBT are needed for leukemic patients with positive MRD pre-CBT. 


\section{CONDENSED ABSTRACT}

- Patients with detectable MRD pre-CBT have a higher risk of relapse than those without $(\mathrm{HR}=1.8, \mathrm{P}=0.003)$.

- Patients with detectable MRD pre-CBT have a lower LFS than those without $(\mathrm{HR}=1.4, \mathrm{P}=0.008)$.

\section{BACKGROUND}

Allogeneic hematopoietic cell transplantation (allo-HCT) is the treatment of choice for fit patients with high-risk acute myeloid leukemia (AML) or acute lymphoblastic leukemia (ALL) ${ }^{1-8}$. Allo-HCT relies both on the conditioning regimen and on immune-mediated graft-versus-leukemia (GvL) effects for leukemia eradication ${ }^{9-11}$. Despite the rapid growth of T-cell replete HLA-haploidentical transplantation ${ }^{12}$, umbilical cord blood transplantation (CBT) has remained an alternative option for patients with high-risk acute leukemia without an HLA-identical sibling donor ${ }^{13-18}$.

During the last decade, several reports have highlighted the negative impact of detectable measurable residual disease (MRD) at transplantation on transplantation outcomes in patients transplanted from either HLA-matched related or unrelated donors, as well as in those given cells from HLA-haploidentical donors ${ }^{19-25}$. This remained true in patients in second complete remission (CR) at transplantation ${ }^{26}$. Interestingly, the negative impact of detectable MRD at transplantation holds true in large registry studies in which various techniques (depending on transplant center) were used for MRD detection²1,27,28. However, a recent report has demonstrated a lower 
incidence of relapse with double CBT than with HLA-matched transplantation among patients with detectable MRD at transplantation ${ }^{15}$. This is in line with emerging data suggesting higher GvL effects with CBT and one might question whether MRD has an impact on CBT outcome.

In this report, we assess the impact of detectable MRD at transplantation on CBT outcomes in a relatively large cohort of patients with acute leukemia in complete remission (CR) reported to the Acute Leukemia Working Party (ALWP) of the European society for Blood and Marrow Transplantation (EBMT) registry and to Eurocord.

\section{METHODS}

\section{Patients and inclusion criteria}

This is a retrospective study from the ALWP of the EBMT and from Eurocord. The EBMT registry is a voluntary working society of more than 500 transplant centers, participants of which are required once a year to report all consecutive hematopoietic stem cell transplantations and follow-up. Audits are routinely performed to check for data accuracy. Eurocord collects data on CBT carried out in more than 50 countries worldwide covering > 500 transplant centers (mainly EBMT).

Inclusion criteria included adult patients (defined as $\geq 18$ years of age at transplantation), with AML or ALL, single or double CBT as first allo-HCT from 2002-2017 in an EBMT-affiliated 
center, in first or second CR at transplantation, and known MRD status at the time of transplantation.

Reduced intensity conditioning (RIC) was defined as regimens combining fludarabine with either $<6$ Gy total body irradiation (TBI), $\leq 8 \mathrm{mg} / \mathrm{kg}$ busulfan, or $\leq 140$ $\mathrm{mg} / \mathrm{m}^{2}$ melphalan or with other nonmyeloablative drugs as previously reported ${ }^{29}$. HLAcompatibility included antigen level typing for HLA-A and -B and allele level typing for HLA-DRB1. Cord blood units were generally 4-6/6 HLA-A, -B and -DRB1 matched to the recipient. Acute and chronic graft-versus-host disease (GVHD) were graded according to previously reported criteria ${ }^{30}$.

\section{MRD detection}

Several techniques with various thresholds were used for MRD detection, depending of the centers. For AML patients, data on MRD methodology was available for 115 patients from 30 centers (supplemental table 1). Most centers (22/30) used multiparameter flow-cytometry (MFC) and PCR techniques with or without next generation sequencing (NGS). The most frequent threshold used was $10^{-5}$ for PCR techniques and $10^{-4}$ for MFC (supplemental table 1). For ALL patients, data on MRD methodology was available for 73 patients from 28 centers. Eighteen centers used MFC plus PCR techniques with or without NGS while 22 others used PCR techniques only. The most frequent threshold used was $10^{-5}$ for PCR techniques and $10^{-4}$ for MFC (supplemental table 1 ). 


\section{Statistical analyses}

Analyses were carried out on data from all patients meeting the inclusion/exclusion criteria. Start time was the day of CBT for all endpoints. Patients were censored at the time of last follow-up. Neutrophil engraftment was defined as the first of 3 consecutive days with a neutrophil count of at least $0.5 \times 10^{9} / \mathrm{L}$. Relapse was defined as the presence of $5 \%$ bone marrow blasts and/or reappearance of the underlying disease. Non-relapse mortality (NRM) was defined as death without evidence of relapse or progression. Overall survival (OS) was defined as the time from CBT to death, regardless of the cause. The primary endpoint of the study was leukemia-free survival (LFS) according to MRD status. Events in the composite endpoint LFS included relapse and death, whichever occurred first.

Cumulative incidence functions were used to estimate relapse incidence and NRM in a competing risk setting, because death and relapse compete with each other. To estimate the cumulative incidence of acute and chronic GVHD, we considered relapse and death to be competing events. Events in the composite endpoint GVHD-free and relapse free survival (GRFS) included grade III-IV acute GVHD, extensive chronic GVHD, relapse or death ${ }^{31}$. The Kaplan-Meier method was used to estimate OS, LFS and GRFS.

Univariate analyses were performed using Gray's test for cumulative incidence functions and the log-rank test for OS, LFS and GRFS. Multivariate Cox models were used to adjust the comparison of transplantation outcomes in patients with, versus without, 
evidence of MRD at transplantation for possible imbalance between groups. Factors included in the Cox models comprised detectable MRD or not, diagnosis (AML versus ALL), age, year of transplantation, second versus first CR, myeloablative versus RIC regimen, double versus single CBT, in vivo T cell depletion or not, and center (frailty). All tests were two sided. The type I error rate was fixed at 0.05 for determination of factors associated with time to event outcomes. Statistical analyses were performed with SPSS 19 (SPSS Inc, Chicago, IL), and R 3.4.3 (R Development Core Team, Vienna, Austria) software packages.

\section{RESULTS}

\section{Patients}

A total of 506 patients met the inclusion/exclusion criteria and were reported in the study (Table 1). Among them, 317 patients had AML and 189 had ALL (including 102 patients with Philadelphia chromosome positive (Phi-pos) ALL). Patients received either single $(n=227)$ or double unit CBT $(n=279)$. Disease status was first CR in 320 patients and second CR in the remaining 186 patients. MRD positivity was detected in 169 (33\%) patients while the remaining 337 patients were MRD negative at CBT. MRD was more frequently detected in ALL than in AML patients $(\mathrm{P}=0.02)$, in patients given single CBT than in those receiving double CBT $(\mathrm{P}=0.02)$, and in those given in vivo $\mathrm{T}$-cell depletion of the donor graft $(\mathrm{P}=0.006)$. 


\section{Engraftment and GVHD}

At 60 days after CBT, neutrophil engraftment was achieved by 91\% (95\% CI 87\%-94\%) of MRD negative patients versus $85 \%$ (95\% CI 79\%-90\%) of those with measurable MRD (P=0.05). The 100-day cumulative incidences of grade II-IV and of III-IV acute GVHD were 34\% (95\% CI 28\%-39\%) and 15\% (95\% CI 11\%-19\%) respectively, in MRD negative patients, versus $37 \%$ (95\% CI 29\%-44\%, P=0.5) and 16\% (95\% CI 11\%-22\%, $\mathrm{P}=0.6$ ). On multivariate analysis, the only factor associated with a lower incidence of grade II-IV acute GVHD was in vivo T cell depletion (HR=0.5, 95\% CI 0.4-0.8, P=0.001) (Supplemental table 2).

The 2-year cumulative incidences of chronic and extensive chronic GVHD were 33\% (95\% CI 27\%-38\%) and 12\% (95\% CI 8\%-16\%) respectively in MRD negative patients, versus 25\% (95\% CI 18\%-32\%, P=0.2) and 13\% (95\% CI 8\%-19\%, P=0.4). On multivariate analysis, no factor was associated with chronic GVHD.

\section{Relapse and NRM}

At 2 years, relapse incidence was 18\% (95\% CI 14\%-22\%) in patients with MRD negativity versus $33 \%(95 \%$ CI $26 \%-41 \%, \mathrm{P}<0.001)$ in those with MRD positivity at transplantation (Figure 1). This negative effect of MRD positivity on relapse was observed both in patients with AML and in those with ALL (independently of Phi 
positivity), and was also observed both in patients in first CR and in those in second CR (Supplemental Tables 3-6). In the subgroup of patients with AML, poor risk cytogenetics (according to the MRC classification ${ }^{32}$ ) was associated with higher relapse incidence in comparison to good/intermediate risk cytogenetics (at 2-year 29\% (95\% CI, 16\%-43\%) vs $22 \%(95 \% \mathrm{CI}, 15 \%-29 \%), \mathrm{P}=0.02)$. Restricting the analyses in AML patients with good/intermediate risk cytogenetics $(n=271)$, MRD positivity $(n=82)$ remained significantly associated with a higher risk of relapse $(28 \%$ (95\% CI, 18\%-38\%) vs 16\% (95\% CI, 11\%-22\%), P=0.046; supplemental table 7). On multivariate analysis, MRD positivity was associated with an increased risk of relapse (HR=1.8, 95\% CI 1.2-2.6, $\mathrm{P}=0.003$ ) (Table 2). Other factors associated with risk of relapse included the use of RIC regimen $(\mathrm{HR}=1.8,95 \% \mathrm{CI} 1.2-2.9, \mathrm{P}=0.01)$ and in vivo $\mathrm{T}$ cell depletion $(\mathrm{HR}=2.2,95 \% \mathrm{CI}$ 1.4-3.4, $\mathrm{P}<0.001)$

\section{LFS, GRFS}

Two-year LFS was 57\% (95\%CI, 51\%-63\%) in MRD negative patients versus 38\% (95\%CI, 30\%-45\%) in those with MRD positivity at CBT $(\mathrm{P}<0.001)$ (Figure 1$)$. There was no statistical interaction between any variable and the association of MRD status with LFS. Furthermore, as shown in Figure 2, detectable MRD at transplantation was associated with worse (or a trend towards worse) LFS in each assessed subgroup (single versus double CBT, AML versus ALL, Phi positive versus Phi negative ALL). Specifically, 
among ALL patients, 2-year LFS was 55\% (95\%CI, 46\%-65\%) in MRD negative patients versus $33 \%(95 \% \mathrm{CI}, 22 \%-44 \%)$ in $\mathrm{MRD}$ positive ones $(\mathrm{P}=0.002)$ while among $\mathrm{AML}$ patients the figures were $58 \%$ (95\%CI, 51\%-65\%) versus $41 \%$ (95\%CI, 31\%-52\%), respectively $(\mathrm{P}=0.02)$. Restricting the analyses to AML patients with good/intermediate risk cytogenetics ${ }^{32}$, 2-year LFS was 59\% (95\% CI, 51\%-66\%) in MRD negative patients, versus 44\% (95\% CI, 32\%-55\%, $\mathrm{P}=0.019)$ in MRD positive ones. Further, interestingly, the negative impact of MRD positivity was at least as much marked in patients in second CR than in those in first CR (Figure 2). Importantly, MRD positivity remained associated with a worse LFS on multivariate analysis (HR=1.42, 95\% CI1.1-1.84 P=0.008). Other factors associated with LFS included second versus first CR at transplantation $(H R=1.33$, 95\%CI 1.01-1.76, $\mathrm{p}=0.04$ ) and in vivo $\mathrm{T}$ cell depletion (HR=1.92, 95\% CI 1.41-2.61, $\mathrm{P}=0.014$ ) (Table 2).

Two-year GRFS was 43\% (95\%CI, 37\%-49\%) in MRD negative patients versus 31\% (95\%CI, 24\%-38\%) in those with MRD positivity at CBT (P=0.005) (Figure 1). There was no statistical interaction between diagnostic group and the association of MRD status with GRFS. Specifically, among ALL patients, 2-year GRFS was 37\% (95\%CI, 28\%-50\%) in MRD negative patients versus 27\% (95\%CI, 16\%-37\%) in MRD positive ones $(\mathrm{P}=0.08)$ while among AML patients the figures were 46\% (95\%CI, 39\%-53\%) versus $35 \%(95 \% \mathrm{CI}, 24 \%-45 \%)$, respectively $(\mathrm{P}=0.046)$. On multivariate analysis $\mathrm{MRD}$ positivity at transplantation was associated with worse GRFS (HR=1.3, 95\%CI 1.03-1.65, $\mathrm{P}=0.029)$. No other factor was significantly associated with GRFS. 
Two-year OS was 60\% (95\%CI, 55\%-66\%) in MRD negative patients versus 48\% (95\%CI, 39\%-56\%) in those with MRD positivity at CBT (P=0.004) (Figure 1). There was no statistical interaction between diagnostic group and the association of MRD status with OS (Figure). Among ALL patients, the 2-year OS was 60\% (95\%CI, 50\%-69\%) in MRD negative patients versus $47 \%$ (95\%CI, 35\%-59\%) in MRD positive ones ( $\mathrm{P}=0.02)$ while among AML patients the figures were 60\% (95\%CI, 53\%-67\%) versus $48 \%$ (95\%CI, 37\%-59\%), respectively $(\mathrm{P}=0.049)$. Restricting the analyses to AML patients with good/intermediate risk cytogenetics 32 , 2-year OS was 62\% (95\% CI, 54\%-69\%) in MRD negative patients, versus $50 \%(95 \% \mathrm{CI}, 37 \%-61 \%, \mathrm{P}=0.034)$ in $\mathrm{MRD}$ positive ones. Further, interestingly, the negative impact of MRD positivity was as much marked in patients in second CR as it was in those in first CR (Figure 2). On multivariate analysis there was a trend for worse OS in patients with detectable MRD (HR=1.3, 95\%CI 0.981.71, $\mathrm{P}=0.065)$. Other factors associated with OS included older age (per decade, $\mathrm{HR}=1.13,95 \%$ CI 1.01-1.27, $\mathrm{P}=0.03)$, second versus first $\mathrm{CR}$ at transplantation $(\mathrm{HR}=1.45$, 95\%CI 1.08-1.94, $\mathrm{p}=0.01)$ and in vivo $\mathrm{T}$ cell depletion ( $\mathrm{HR}=1.78,95 \% \mathrm{CI} 1.28-2.47$, $\mathrm{P}<0.001$ ) (Table 2).

At the time of analysis, death from the underlying disease of MRD negative and MRD positive patients was $14 \%$ and $18 \%$ respectively, while $5 \%$ and $11 \%$ respectively, died from GVHD. 


\section{DISCUSSION}

Several reports have demonstrated the negative impact of detectable MRD at transplantation on transplantation outcomes in patients given grafts from HLA-matched or HLA-haploidentical donors ${ }^{19,20,27,28}$. However, the impact of detectable MRD at transplantation on CBT outcome remains debatable. Tucunduva et al. first reported that in the setting of Phi-positive ALL ( $n=98)$, detectable MRD ( $n=59)$ was associated with a higher risk of relapse following CBT ${ }^{33}$. In contrast, a study by Milano et al. of data from 137 patients with AML, ALL or myelodysplastic syndrome, reported that detectable MRD at transplantation $(\mathrm{n}=45)$ was not associated with a significantly higher risk of relapse following double CBT (HR=1.43, 95\% CI : 0.58-3.57). The authors also reported a lower incidence of relapse with double CBT than with HLA-matched or HLA-mismatched transplantation, among MRD positive patients ${ }^{15}$. These data, which are in line with emerging data suggesting higher GvL effects in (double) CBT $^{34-36}$, prompted us to assess the impact of detectable MRD on CBT outcomes in a relatively large cohort of patients with AML or ALL in first or second CR at transplantation.

First, we observed that detectable MRD at CBT was associated with higher risk of relapse leading to worse LFS, worse GRFS and a suggestion for worse OS. This impact of detectable MRD was observed in all subgroups but perhaps appeared to be less marked among patients with Phi-positive ALL, possibly because many of these patients might have received a tyrosine kinase inhibitor after CBT (or possibly due to a lack of 
statistical power in subgroup analyses). Interestingly, the impact of detectable MRD at CBT was at least as strong in patients in CR2 at transplantation as in those in first CR. Nevertheless, despite detectable MRD at transplantation being associated with poorer CBT outcomes it should be stressed that CBT outcomes among MRD positive patients remained encouraging with approximately half of the patients still alive 2 years after CBT.

This study also confirms several observations made previously regarding CBT for acute leukemia such as similar LFS with both RIC and MAC regimens ${ }^{29,37}$, similar LFS with double or single unit CBT 10,38, and a detrimental impact of in vivo T-cell depletion on CBT outcome $18,39,40$.

There are some limitations to our study including the fact that MRD assessment was not standardized and that the method of MRD detection varied among centres, or the fact that we lack data on the use of post-transplant anti-leukemia agents (such as tyrosine kinase inhibitor in case of Phi-positive ALL or FLT3-mutated AML5,41,42, or hypomethylating agents ${ }^{43,44}$ ).

\section{CONCLUSIONS}

In summary, our results indicate that among acute leukemia patients undergoing CBT, achieving MRD negativity at time of transplantation is associated with a lower risk of relapse translating into better LFS. Novel strategies are needed for those leukemic patients with MRD positivity pre-CBT aiming at either achieving MRD negativity at CBT 
or preventing relapse following CBT by receiving post-transplant anti-leukemic drugs and/or immunotherapy and thus further improving CBT results.

\section{DECLARATIONS}

\section{Ethics approval and consent to participate}

The scientific board of the ALWP of the EBMT approved this study.

\section{Consent for publication}

NA

\section{Availability of data and materials}

ML, AN and MM had full access to all the data in the study (available upon data specific request).

\section{Competing interests}

Frédéric Baron has received travel grants from Celgene, Abbvie, Novartis and Sanofi as well as honoraria from Merck and Abbvie. The remaining authors declare that they have no relevant conflict of interest.

\section{Funding}

FB is Senior Research Associate at the National Fund for Scientific Research (FNRS) Belgium. 


\section{Authors' contributions}

FBa wrote the manuscript, designed the study, and interpreted the data; ML designed the study, analyzed and interpreted the data, and edited the manuscript; AR, AN and MM designed the study, interpreted the data and edited the manuscript; EG helped in the study design and edited the manuscript; JS, SR, HLW, MP, JMR, ED, AR, PSR and TR reviewed the manuscript and provided clinical data. All authors approved the final version of the manuscript.

\section{Acknowledgements}

We are grateful to Emmanuelle Polge and Audrey Mailhol from the office of the ALWP of EBMT, as well as to Chantal Kenzey and Fernanda Volt from the Eurocord study office.

\section{REFERENCES}

1. Baron F, Efficace F, Cannella L, et al. Long-term follow-up of a trial comparing post-remission treatment with autologous or allogeneic bone marrow transplantation or intensive chemotherapy in younger acute myeloid leukemia patients. Haematologica. 2019.

2. Versluis J, In 't Hout FE, Devillier R, et al. Comparative value of post-remission treatment in cytogenetically normal AML subclassified by NPM1 and FLT3-ITD allelic ratio. Leukemia. 2017;31(1):26-33.

3. Dhedin N, Huynh A, Maury S, et al. Role of allogeneic stem cell transplantation in adult patients with Ph-negative acute lymphoblastic leukemia. Blood. 2015;125(16):2486-2496; quiz 2586.

4. Giebel S, Marks DI, Boissel N, et al. Hematopoietic stem cell transplantation for adults with Philadelphia chromosome-negative acute lymphoblastic leukemia in first remission: a position statement of the European Working Group for Adult Acute Lymphoblastic Leukemia (EWALL) and the Acute Leukemia Working Party 
of the European Society for Blood and Marrow Transplantation (EBMT). Bone marrow transplantation. 2018.

5. Giebel S, Czyz A, Ottmann 0, et al. Use of tyrosine kinase inhibitors to prevent relapse after allogeneic hematopoietic stem cell transplantation for patients with Philadelphia chromosome-positive acute lymphoblastic leukemia: A position statement of the Acute Leukemia Working Party of the European Society for Blood and Marrow Transplantation. Cancer. 2016;122(19):2941-2951.

6. Canaani J. Management of AML Beyond " $3+7$ " in 2019. Clinical Hematology International. 2019;1(1):10-18.

7. Baron F, Efficace F, Cannella L, et al. Impact of the type of anthracycline and of stem cell transplantation in younger patients with acute myeloid leukaemia: long-term follow up of a phase III study. Am J Hematol. 2020.

8. Poire X, Labopin M, Polge E, et al. Hematopoietic stem cell transplantation for adult patients with isolated NPM1 mutated acute myeloid leukemia in first remission. Am J Hematol. 2019;94(2):231-239.

9. Baron F, Labopin M, Niederwieser D, et al. Impact of graft-versus-host disease after reduced-intensity conditioning allogeneic stem cell transplantation for acute myeloid leukemia: a report from the Acute Leukemia Working Party of the European group for blood and marrow transplantation. Leukemia. 2012;26(12):2462-2468.

10. Baron F, Ruggeri A, Beohou E, et al. Single- or double-unit UCBT following RIC in adults with AL: a report from Eurocord, the ALWP and the CTIWP of the EBMT. Journal of hematology \& oncology. 2017;10(1):128.

11. Dickinson AM, Norden J, Li S, et al. Graft-versus-Leukemia Effect Following Hematopoietic Stem Cell Transplantation for Leukemia. Frontiers in immunology. 2017;8:496.

12. Passweg JR, Baldomero $\mathrm{H}$, Bader $\mathrm{P}$, et al. Use of haploidentical stem cell transplantation continues to increase: the 2015 European Society for Blood and Marrow Transplant activity survey report. Bone marrow transplantation. 2017.

13. Barker JN, Weisdorf DJ, Defor TE, et al. Transplantation of 2 partially HLAmatched umbilical cord blood units to enhance engraftment in adults with hematologic malignancy. Blood. 2005;105(3):1343-1347.

14. Ballen KK, Gluckman E, Broxmeyer HE. Umbilical cord blood transplantation: the first 25 years and beyond. Blood. 2013;122(4):491-498.

15. Milano F, Gooley T, Wood B, et al. Cord-Blood Transplantation in Patients with Minimal Residual Disease. The New England journal of medicine. 2016;375(10):944-953.

16. Baron F, Labopin M, Ruggeri A, et al. Cord blood transplantation is associated with good outcomes in secondary Acute Myeloid Leukaemia in first remission. $J$ Intern Med. 2018.

17. Baron F, Labopin M, Ruggeri A, et al. Impact of Donor Type in Patients with AML Given Allogeneic Hematopoietic Cell Transplantation After Low-Dose TBI-Based 
Regimen. Clinical cancer research : an official journal of the American Association for Cancer Research. 2018.

18. Baron F, Ruggeri A, Beohou E, et al. Occurrence of graft-versus-host disease increases mortality after umbilical cord blood transplantation for acute myeloid leukemia: a report from Eurocord and the ALWP of the EBMT. J Intern Med. 2018;283(2):178-189.

19. Zhou Y, Othus M, Araki D, et al. Pre- and post-transplant quantification of measurable ('minimal') residual disease via multiparameter flow cytometry in adult acute myeloid leukemia. Leukemia. 2016;30(7):1456-1464.

20. Thol F, Gabdoulline R, Liebich A, et al. Measurable residual disease monitoring by NGS before allogeneic hematopoietic cell transplantation in AML. Blood. 2018;132(16):1703-1713.

21. Pavlu J, Labopin M, Niittyvuopio R, et al. Measurable residual disease at myeloablative allogeneic transplantation in adults with acute lymphoblastic leukemia: a retrospective registry study on 2780 patients from the acute leukemia working party of the EBMT. Journal of hematology \& oncology. 2019;12(1):108.

22. Srour SA, Saliba RM, Bittencourt MCB, et al. Haploidentical transplantation for acute myeloid leukemia patients with minimal/measurable residual disease at transplantation. Am J Hematol. 2019;94(12):1382-1387.

23. Press RD, Eickelberg G, Froman A, et al. Next-generation sequencing-defined minimal residual disease before stem cell transplantation predicts acute myeloid leukemia relapse. Am J Hematol. 2019;94(8):902-912.

24. Zhao XS, Liu YR, Xu LP, et al. Minimal residual disease status determined by multiparametric flow cytometry pretransplantation predicts the outcome of patients with ALL receiving unmanipulated haploidentical allografts. Am J Hematol. 2019;94(5):512-521.

25. Short NJ, Jabbour E, Albitar M, et al. Recommendations for the assessment and management of measurable residual disease in adults with acute lymphoblastic leukemia: A consensus of North American experts. Am J Hematol. 2019;94(2):257-265.

26. Gilleece MH, Labopin M, Savani BN, et al. Allogeneic haemopoietic transplantation for acute myeloid leukaemia in second complete remission: a registry report by the Acute Leukaemia Working Party of the EBMT. Leukemia. 2019.

27. Gilleece $\mathrm{MH}$, Labopin M, Yakoub-Agha I, et al. Measurable residual disease, conditioning regimen intensity, and age predict outcome of allogeneic hematopoietic cell transplantation for acute myeloid leukemia in first remission: A registry analysis of 2292 patients by the Acute Leukemia Working Party European Society of Blood and Marrow Transplantation. Am J Hematol. 2018;93(9):1142-1152.

28. Canaani J, Labopin M, Huang XJ, et al. Minimal residual disease status predicts outcome of acute myeloid leukaemia patients undergoing T-cell replete haploidentical transplantation. An analysis from the Acute Leukaemia Working 
Party (ALWP) of the European Society for Blood and Marrow Transplantation (EBMT). Br J Haematol. 2018.

29. Baron F, Ruggeri A, Beohou E, et al. RIC versus MAC UCBT in adults with AML: A report from Eurocord, the ALWP and the CTIWP of the EBMT. Oncotarget. 2016;7(28):43027-43038.

30. Glucksberg H, Storb R, Fefer A, et al. Clinical manifestations of graft-versus-host disease in human recipients of marrow from HL-A-matched sibling donors. Transplantation. 1974;18:295-304.

31. Ruggeri A, Labopin M, Ciceri F, Mohty M, Nagler A. Definition of GvHD-free, relapse-free survival for registry-based studies: an ALWP-EBMT analysis on patients with AML in remission. Bone marrow transplantation. 2016;51(4):610611.

32. Grimwade D, Hills RK, Moorman AV, et al. Refinement of cytogenetic classification in acute myeloid leukemia: determination of prognostic significance of rare recurring chromosomal abnormalities among 5876 younger adult patients treated in the United Kingdom Medical Research Council trials. Blood. 2010;116(3):354-365.

33. Tucunduva L, Ruggeri A, Sanz G, et al. Impact of minimal residual disease on outcomes after umbilical cord blood transplantation for adults with Philadelphiapositive acute lymphoblastic leukaemia: an analysis on behalf of Eurocord, Cord Blood Committee and the Acute Leukaemia working party of the European group for Blood and Marrow Transplantation. Br J Haematol. 2014;166(5):749-757.

34. Verneris MR, Brunstein CG, Barker J, et al. Relapse risk after umbilical cord blood transplantation: enhanced graft-versus-leukemia effect in recipients of 2 units. Blood. 2009;114(19):4293-4299.

35. Barker J, Hanash A. Cord blood T cells are "completely different". Blood. 2015;126(26):2778-2779.

36. Lamers $\mathrm{CH}$, Wijers $\mathrm{R}$, van Bergen $\mathrm{CA}$, et al. CD4+ T-cell alloreactivity towards mismatched HLA-class II alleles early after double umbilical cord blood transplantation (dUCBT). Blood. 2016.

37. Baron F, Labopin M, Ruggeri A, et al. Unrelated cord blood transplantation for adult patients with acute myeloid leukemia: higher incidence of acute graftversus-host disease and lower survival in male patients transplanted with female unrelated cord blood-a report from Eurocord, the Acute Leukemia Working Party, and the Cord Blood Committee of the Cellular Therapy and Immunobiology Working Party of the European Group for Blood and Marrow Transplantation. Journal of hematology \& oncology. 2015;8(1):107.

38. Ruggeri A, Sanz G, Bittencourt H, et al. Comparison of outcomes after single or double cord blood transplantation in adults with acute leukemia using different types of myeloablative conditioning regimen, a retrospective study on behalf of Eurocord and the Acute Leukemia Working Party of EBMT. Leukemia. 2014;28(4):779-786. 
39. Pascal L, Mohty M, Ruggeri A, et al. Impact of rabbit ATG-containing myeloablative conditioning regimens on the outcome of patients undergoing unrelated single-unit cord blood transplantation for hematological malignancies. Bone marrow transplantation. 2015;50(1):45-50.

40. Pascal L, Tucunduva L, Ruggeri A, et al. Impact of ATG-containing reducedintensity conditioning after single- or double-unit allogeneic cord blood transplantation. Blood. 2015;126(8):1027-1032.

41. Bazarbachi A, Labopin M, Battipaglia G, et al. Sorafenib improves survival of FLT3-mutated acute myeloid leukemia in relapse after allogeneic stem cell transplantation: a report of EBMT acute leukemia Working Party. Haematologica. 2019.

42. Lee CJ, Savani BN, Mohty M, et al. Post-remission strategies for the prevention of relapse following allogeneic hematopoietic cell transplantation for high-risk acute myeloid leukemia: expert review from the Acute Leukemia Working Party of the European Society for Blood and Marrow Transplantation. Bone marrow transplantation. 2019;54(4):519-530.

43. Ehx G, Fransolet G, de Leval L, et al. Azacytidine prevents experimental xenogeneic graft-versus-host disease without abrogating graft-versus-leukemia effects. Oncoimmunology. 2017;6(5):e1314425.

44. Craddock C, Jilani NY, Siddique S, et al. Tolerability and Clinical Activity of PostTransplantation Azacitidine in Patients Allografted for Acute Myeloid Leukemia Treated on the RICAZA Trial. Biology of blood and marrow transplantation : journal of the American Society for Blood and Marrow Transplantation. 2015. 


\section{FIGURE LEGEND}

Figure 1. Impact of MRD on transplantation outcomes. A) relapse. B) non relapse mortality. C) leukemia-free survival. D) GVHD-free and relapse-free survival. E) overall survival.

Figure 2. Forest-plot showing the impact of detectable MRD (versus not) on leukemiafree survival (A, LFS) and overall survival (B, OS) in various subgroups. 
Table 1. Patient and transplant characteristics

\begin{tabular}{|c|c|c|c|}
\hline & $\begin{array}{l}\text { MRD neg } \\
(n=337)\end{array}$ & $\begin{array}{l}\text { MRD pos } \\
(n=169)\end{array}$ & $\begin{array}{c}\text { Pvalue } \\
1\end{array}$ \\
\hline Median patient age, y (range) & $43(18-70)$ & $41(18-66)$ & 0.46 \\
\hline Patient sex, \# (\%) & & & 0.73 \\
\hline Male & $168(50)$ & $87(51)$ & \\
\hline Female & $169(50)$ & $82(49)$ & \\
\hline KPS, \# (\%) & & & 0.51 \\
\hline$<80$ & $11(4)$ & $4(2)$ & \\
\hline$>=80$ & $291(96)$ & $156(98)$ & \\
\hline Missing & 35 & 9 & \\
\hline Diagnosis, \# (\%) & & & $0.02^{3}$ \\
\hline AML & $223(66)$ & $94(56)$ & \\
\hline Good risk ${ }^{2}$ & 23 & 20 & \\
\hline Intermediate risk ${ }^{2}$ & 87 & 43 & \\
\hline Poor risk ${ }^{2}$ & 34 & 12 & \\
\hline NA / failed & 79 & 19 & \\
\hline ALL & $114(34)$ & $75(44)$ & \\
\hline Phi neg B ALL & 16 & 8 & \\
\hline Phi pos B ALL & 53 & 49 & \\
\hline T ALL & 19 & 9 & \\
\hline ALL missing & 26 & 9 & \\
\hline Status at transplantation, \# (\%) & & & 0.42 \\
\hline CR1 & $209(62)$ & $111(66)$ & \\
\hline CR2 & $128(38)$ & $58(34)$ & \\
\hline Follow-up, mo (IQR) & $40(19-74)$ & $53(19-70)$ & \\
\hline Conditioning regimen, \# (\%) & & & 0.10 \\
\hline Myeloablative & $202(60)$ & $114(67)$ & \\
\hline TBI based & $105(31)$ & $56(33)$ & \\
\hline TBF & $70(21)$ & $43(25)$ & \\
\hline $\mathrm{BuCy}$ & $12(4)$ & $4(2)$ & \\
\hline Other / missing & $15(4)$ & $11(7)$ & \\
\hline Reduced-intensity & $135(40)$ & $55(33)$ & \\
\hline TBI based & $123(36)$ & $46(27)$ & \\
\hline Other / missing & $12(4)$ & $9(5)$ & \\
\hline In vivo $T C D, \#(\%)$ & & & 0.006 \\
\hline Yes & $203(64)$ & $82(51)$ & \\
\hline No & $116(36)$ & $80(49)$ & \\
\hline Missing & 18 & 7 & \\
\hline Units of CBT & & & 0.02 \\
\hline Single & $139(41)$ & $88(52)$ & \\
\hline Double & 198 (59) & $81(48)$ & \\
\hline $\begin{array}{l}\text { Postgrafting immunosuppression, } \\
\text { \# (\%) }\end{array}$ & & & 0.9 \\
\hline CSP alone & $69(22)$ & $41(25)$ & \\
\hline $\mathrm{CSP}+\mathrm{MMF}+/-\mathrm{MTX}$ & $211(66)$ & $102(63)$ & \\
\hline Other & $40(12)$ & $19(11)$ & \\
\hline Missing & 17 & 7 & \\
\hline
\end{tabular}


1, calculated with $\chi^{2}$ statistics for categorical variables and Mann-Whitney test for continuous variables; ${ }^{2}$, cytogenetic risk was categorized according to the MRC classification ${ }^{32} ;{ }^{3}$, refers to the comparison of AML versus ALL; Y, year; mo, month; KPS, Karnofsky score, AML, acute myeloid leukemia; ALL, acute lymphoblastic leukemia; Phi, Philadelphia chromosome; TBI, total body irradiation; TBF, thiotepa, busulfan and fludarabine; BuCy, busulfan and cyclophosphamide; IQR, interquartile range; CR, complete remission; TCD, T-cell depletion; CBT, cord blood transplantation; \#, number of patients; tacro, tacrolimus; CSP, cyclosporine A; MMF, mycophenolate mofetil; MTX, methotrexate.

Table 2: Multivariate analyses for CBT outcomes.

\begin{tabular}{|c|c|c|c|c|c|c|c|c|c|c|}
\hline & \multicolumn{2}{|l|}{ RELAPSE } & \multicolumn{2}{|l|}{ NRM } & \multicolumn{2}{|l|}{ LFS } & \multicolumn{2}{|l|}{ os } & \multicolumn{2}{|l|}{ GRFS } \\
\hline & $\mathrm{HR}(95 \% \mathrm{Cl})$ & $p$ value & $\mathrm{HR}(95 \% \mathrm{Cl})$ & $p$ value & $\mathrm{HR}(95 \% \mathrm{Cl})$ & $p$ value & $\mathrm{HR}(95 \% \mathrm{Cl})$ & $p$ value & $\mathrm{HR}(95 \% \mathrm{Cl})$ & $p$ value \\
\hline MRD detectable vs not & $1.78(1.22-2.58)$ & 0.003 & $1.15(0.80-1.66)$ & 0.44 & $1.42(1.1-1.84)$ & 0.008 & $1.3(0.98-1.71)$ & 0.065 & $1.3(1.03-1.65)$ & 0.029 \\
\hline ALL vs AML & $1.33(0.88-2.03)$ & 0.181 & $1.14(0.77-1.69)$ & 0.521 & $1.22(0.92-1.63)$ & 0.168 & $1.09(0.8-1.48)$ & 0.592 & $1.21(0.94-1.57)$ & 0.135 \\
\hline Age (per 10 years) & $0.99(0.85-1.16)$ & 0.91 & $1.16(1-1.35)$ & 0.047 & $1.08(0.97-1.2)$ & 0.169 & $1.13(1.01-1.27)$ & 0.031 & $1.04(0.95-1.15)$ & 0.403 \\
\hline Year of CBT & $0.99(0.93-1.06)$ & 0.82 & $0.96(0.91-1.02)$ & 0.207 & $0.98(0.94-1.02)$ & 0.273 & $0.97(0.925-1.01)$ & 0.17 & $0.99(0.95-1.03)$ & 0.594 \\
\hline CR2 vs CR1 & 1.31 (0.87-1.99) & 0.193 & $1.35(0.93-1.98)$ & 0.119 & $1.33(1.01-1.76)$ & 0.043 & $1.45(1.08-1.94)$ & 0.013 & $1.26(0.99-1.62)$ & 0.064 \\
\hline RIC vs MAC & $1.84(1.16-2.92)$ & 0.01 & $0.829(0.52-1.32)$ & 0.43 & $1.23(0.89-1.7)$ & 0.221 & $1.06(0.75-1.5)$ & 0.741 & $0.93(0.69-1.24)$ & 0.616 \\
\hline DCBT vs SCBT & $1.0(0.65-1.52)$ & 0.992 & $0.71(0.48-1.05)$ & 0.089 & $0.83(0.63-1.11)$ & 0.216 & $0.75(0.55-1.02)$ & 0.067 & $0.91(0.70-1.18)$ & 0.476 \\
\hline in vivo $T C D$ & $2.18(1.39-3.41)$ & 0.001 & $1.69(1.11-2.58)$ & 0.014 & $1.92(1.41-2.61)$ & $<0.001$ & $1.78(1.28-2.47)$ & 0.001 & $1.17(0.89-1.55)$ & 0.261 \\
\hline Centre (frailty) & & 0.924 & & 0.357 & & 0.905 & & 0.701 & & 0.898 \\
\hline
\end{tabular}

NRM, non relapse mortality; LFS, leukemia-free survival; OS, overall survival; GRFS, GVHD-free and relapse free survival; MRD, minimal residual disease; ALL, acute lymphoblastic leukemia; AML, acute myeloid leukemia; CBT, cord blood transplantation; CR, complete remission; RIC, reduced-intensity conditioning regimen; MAC, myeloablative conditioning regimen; dCBT, double unit CBT; sCBT, single unit CBT; TCD, T-cell depletion; HR, hazard ratio; CI, confidence interval. 
Cell Source : DCBT

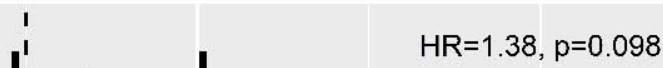

\section{Cell Source : SCBT}
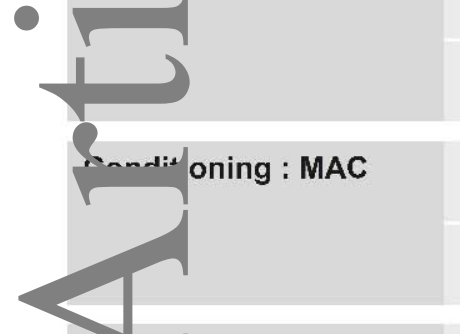

Conditoning : RIC

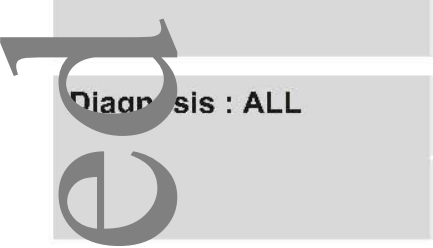

sis : AML
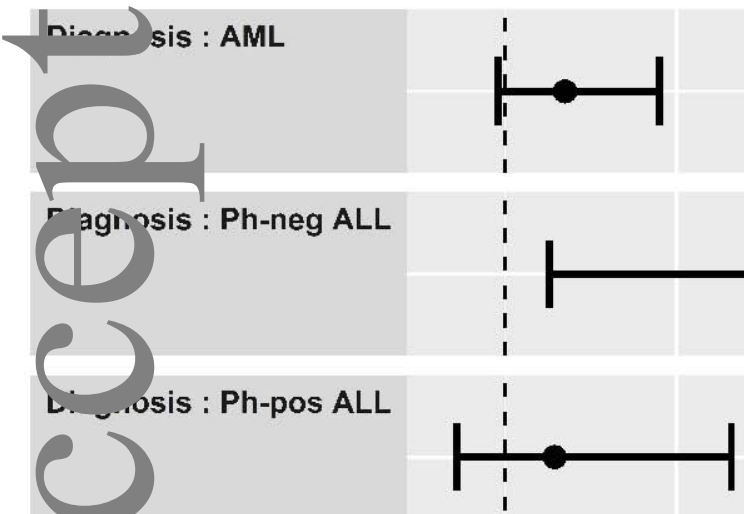

This article'is protected by copyright. All rights ${ }_{4}$ reserved. HR (95\% Confidence Interval) 
Cell Source : DCBT

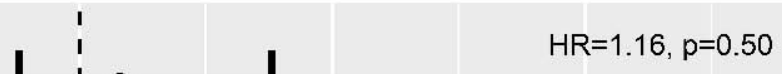

\section{Cell Source : SCBT}

Corrit oning : RIC oning : MAC

Diaan sis : ALL
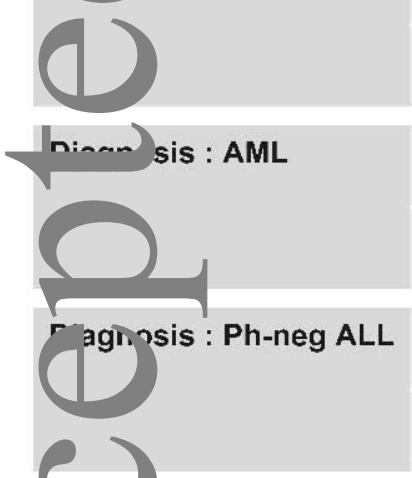

osis : Ph-pos ALL
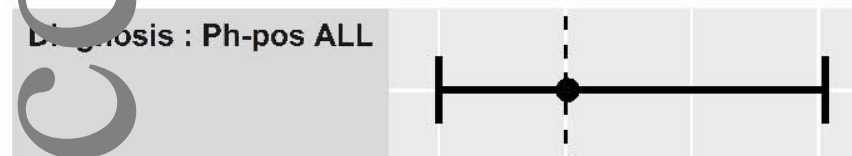

$H R=1.43, p=0.069$

$H R=1.21, p=0.27$

$H R=1.55, p=0.088$

$H R=1.26, p=0.36$
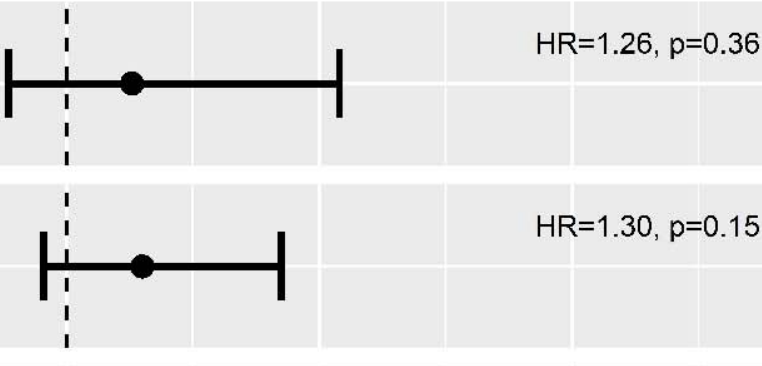

$H R=1.30, p=0.15$
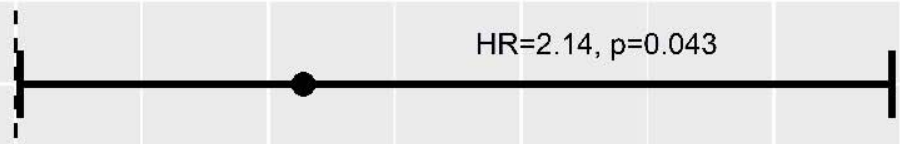

This article is prdtected by copyright. All rights reserved. HR (95\% Confidence Interval) 


\section{A - RI}

- MRD negative MRD positive

Time from transplant (years)

number of at-risk patients

$\begin{array}{lllll}178 & 134 & 98 & 77 & 60\end{array}$

$\begin{array}{lllll}69 & 47 & 37 & 28 & 21\end{array}$

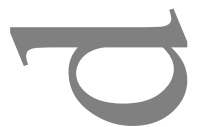

1D - GRFS

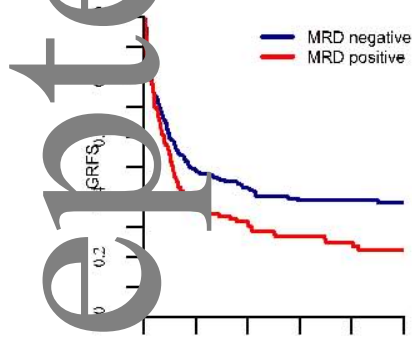

e

Time from transplant (years)

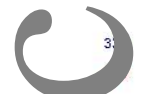

number of at-risk patients

\section{$\begin{array}{lllll}143 & 102 & 74 & 57 & 44\end{array}$}

$\begin{array}{lllll}53 & 37 & 29 & 22 & 15\end{array}$
1B - NRM

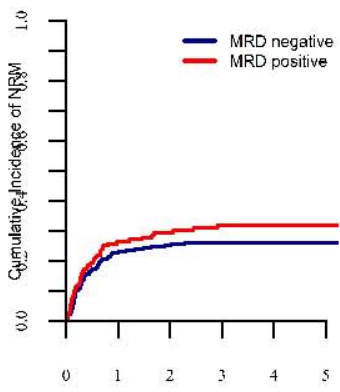

Time from transplant (years)

number of at-risk patients

$\begin{array}{llllll}337 & 178 & 134 & 98 & 77 & 60\end{array}$

$\begin{array}{llllll}169 & 69 & 47 & 37 & 28 & 21\end{array}$

1E - OS

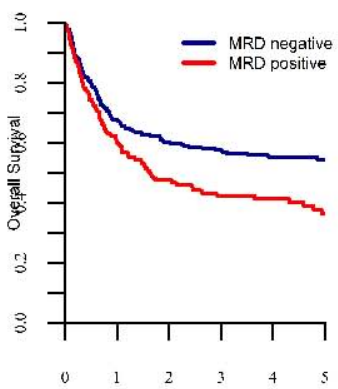

Time from transplant (years)

number of at-risk patients

$\begin{array}{llllll}337 & 197 & 144 & 110 & 84 & 65\end{array}$

$\begin{array}{llllll}169 & 84 & 58 & 47 & 37 & 27\end{array}$
1C - LFS

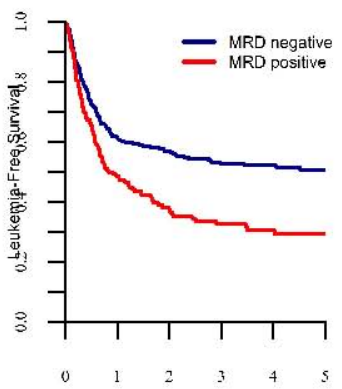

Time from transplant (years) number of at-risk patients

$\begin{array}{llllll}337 & 178 & 134 & 98 & 77 & 60\end{array}$

This article is protected by copyright. All rights reserved. 